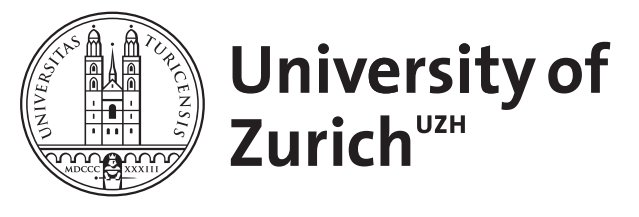

\title{
The Zurich Study XXIV
}

\author{
Ernst, Cécile ; Angst, Jules
}

\begin{abstract}
A Swiss cohort interviewed four times between ages 20 and 30 years reported on a structural aspect of childhood (separation from parents) and emotional aspects (family strain, childhood behavioral and emotional problems). These data were connected with DSM-III-R diagnoses of anxiety and depression, SCL-90R scores (all repeatedly ascertained) and with Freiburg Personality Inventory results at age 30 years. Adult psychopathology, personality deviations, and negative affectivity were not connected with early or later separation, but with a report of family strain and childhood disturbances. As variables associated with later psychiatric symptoms and disorder, interpersonal and subjective aspects of childhood outweigh the fact of separation from parents
\end{abstract}

DOI: https://doi.org/10.1007/bf02900197

Posted at the Zurich Open Repository and Archive, University of Zurich

ZORA URL: https://doi.org/10.5167/uzh-156566

Journal Article

Published Version

Originally published at:

Ernst, Cécile; Angst, Jules (1997). The Zurich Study XXIV. European Archives of Psychiatry and Clinical Neuroscience, 247(2):81-86.

DOI: https://doi.org/10.1007/bf02900197 


\section{Cécile Ernst · Jules Angst \\ The Zurich Study XXIV \\ Structural and emotional aspects of childhood and later psychopathology}

\begin{abstract}
A Swiss cohort interviewed four times between ages 20 and 30 years reported on a structural aspect of childhood (separation from parents) and emotional aspects (family strain, childhood behavioral and emotional problems). These data were connected with DSM-III-R diagnoses of anxiety and depression, SCL-90R scores (all repeatedly ascertained) and with Freiburg Personality Inventory results at age 30 years. Adult psychopathology, personality deviations, and negative affectivity were not connected with early or later separation, but with a report of family strain and childhood disturbances. As variables associated with later psychiatric symptoms and disorder, interpersonal and subjective aspects of childhood outweigh the fact of separation from parents.
\end{abstract}

Key words Early separation - Mother deprivation . Family strain - Childhood problems - Adult psychopathology $\cdot$ FPI

\section{Introduction}

In contrast to the situation after World War II, the present society is less inclined to reject early separations of children from their mothers. The reasons are mainly economic: part-time jobs of the tertiary sector, where women predominate, are one of the few growing sectors of the economy. One-parent families, mainly with female heads, are becoming steadily more frequent, and the en masse entrance of young women with small children into the labour force has been called a "social revolution."

This development is attended by the anxious discussion of the fate of young children who in increasing numbers during their first years do not grow up with one and the same caregiver. Spitz (1954) and Bowlby (1951) in their extremely influential work connected the trauma of

C. Emst (ब) $\cdot$ J. Angst

Psychiatric University Hospital Zurich, P.O. Box 68,

CH-8029 Zurich, Switzerland early separation with mental illness. Both authors particularly stressed the danger of separation from mother during the first 2 years of age. A survey of longitudinal epidemiological studies on childhood conditions and later disorder (Ernst 1993) showed, on the other hand, that childhood and adult disorder is not connected with early separation by itself but with lasting family disadvantage present before and after separation, and that separation at any age is an indicator of a risk to mental health, rather than being a cause of mental illness.

The present paper on childhood conditions of young adults who took part in an epidemiological study (19781988) reports a retrospective assessment of childhood regarding early and later separation, family disadvantage, and childhood behavioral and emotional problems, and an assessment of personality at age $29-30$ years. The longitudinal aspect consists in an assessment of psychiatric symptoms and psychiatric disorder over 10 years, which was completely independent of the assessment of childhood conditions. The diagnoses of depression and anxiety are connected with structural and evaluative data on early and later childhood, and the latter's weight for later development is discussed.

\section{Materials and methods}

The subjects of this investigation were taken from the Zurich Study, a longitudinal epidemiological investigation of young adults from the Canton Zurich, Switzerland, born in 1959 (males) and 1958 (females; Angst et al 1984). After a questionnaire screening in 1978 of 4547 subjects, a sample of 292 males and 299 females (total $n=591$ ) was selected according to scores on the SCL-90R (Derogatis 1977) with two thirds of the sample being high scorers. Up to 1988 four interviews were given (Fig. 1). They were conducted by trained psychologists at the home of the subjects. In 1986,457 subjects, and in 1988, 424 subjects were interviewed (response rate 1988: 71.7\%). The SCL-90R was presented at each interview and in 1988 also the Freiburg Personality Inventory (Fahrenberg et al. 1973), where additionally to the evaluation proposed by the authors the results of a factor analysis proposed by Angst and Clayton (1986) is given. In 1988 the subjects were 2930 years old.

In 1988 questions on family structure assessed whether the subject had lived with both natural parents up to age 16 years or if not, 


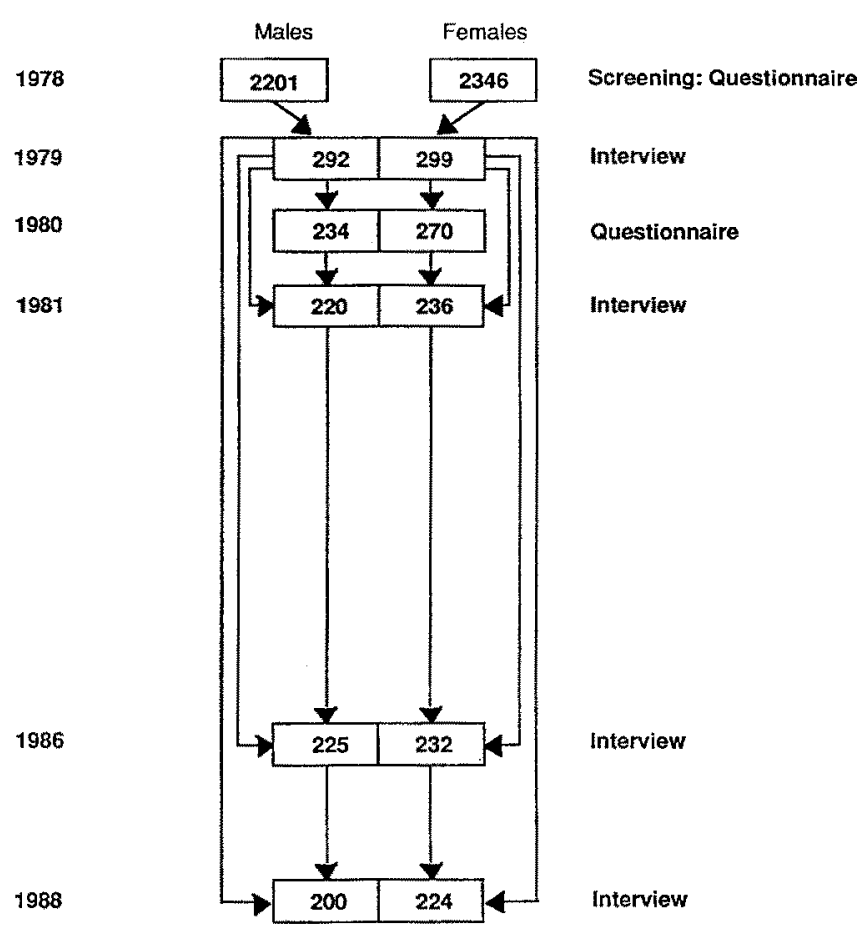

Fig. 1 Design of the Zurich Study

\section{Results}

Childhood separations were reported by 67 subjects, i.e., by $15.8 \%$ of the 424 subjects who were interviewed in 1988. Of this group, 32 were males and 35 were females. Twenty-one subjects experienced separation during the first 2 years of life, 10 between ages 2 and 5 years, and 36 subjects between age 6 years and their sixteenth birthday. These data concern the age at the incidence of separation. In all but 4 subjects separation outlasted childhood. In Table 1 the living situations after separation for all 67 subjects are described.

The main reason for the separation from parents was divorce. Between ages 6 and 16 years, in 28 of 36 cases parents were divorced and the child continued to stay with mother. Thus, notwithstanding a breakup of the family, $77.7 \%$ of those separated at school age continued to stay with mother.

At ages 0-2 years, 5 of 21 children from atypical families ( 3 from broken, 2 from incomplete families) stayed with mother $(23.8 \%)$; at age 3-5 years, 2 children out of $10(20 \%)$. Thus, separation at age $0-5$ years mainly means separation from mother and that mainly very young children are adopted or fostered or brought up by grandparents (staying with mother age $0-5$ vs age $6-10$ years; $P \leq$ $0.01)$.

Institutionalization after a first separation was reported for 7 of 21 children at ages 0 to 2 years, and for 1 child at age 3-5 years, but not for older children. Secondary institutionalization after an unsatisfactory first placement occurred with another 11 children.

Four children were reunited with their natural parents after separation; thus, reunion was very rare. Only 2 subjects reported marriage or remarriage of their mother and living with stepfather.

In the following analyses we restrict ourselves to the groups that were separated at ages $0-2$ and 6-16 years. $(n=21, n=36$, total $n=57)$, i.e., to early and to late separation. In order to obtain as clear a picture as possible of tion for childhood anxiety. The items are weighted according to the specificity of the situation. Being unpopular as a child is strongly associated with later psychiatric disorder (Masten and Coatsworth 1995); according to DSM-III-R (p. 63) overanxious children are at risk for later anxiety disorders. In 1988, questions regarded family adversities (Rutter et al. 1976; Steinhausen 1985) and family structure. Adversities were chronic illness and/or psychiatric treatment of parents and/or sib, parental discord, severe conflict with parents, severe financial problems of parents, severe punishments; and subjectively felt lack of care. They were added to a family strain score (FS; see Table 2).

At each interview the presence of symptoms of anxiety and depression was ascertained and computerized DSM-III-R diagnoses of depression and anxiety disorders were generated. A longitudinal diagnosis of depression means that for over 10 years at least once a diagnosis of major depressive episode and/or dysthymia and/or recurrent brief depression (Angst et al. 1990) was given. A longitudinal diagnosis of anxiety comprises DSM-III-R general anxiety, panic disorder, and recurrent brief anxiety (Angst and Wicki 1992). These longitudinal diagnoses are more comprehensive than cross-sectional diagnoses and also include brief intermittent syndromes. A diagnosis of sociopathy corresponds to DSM-III-R criteria.
Table 1 Age at separation and placement after separation/incomplete families (1988)

\begin{tabular}{lll} 
Age (years) & \\
\hline $0-2$ & $3-5$ & $6-15$ \\
$(n=21)$ & $(n=10)$ & $(n=36)$ \\
\hline
\end{tabular}

Separation and placement

Both parents $\rightarrow$ mother

Both parents $\rightarrow$ father

Both parents or mother

$\rightarrow$ grand parents

Both parents or mother

$\rightarrow$ adoptive or fostering home

Both parents or mother

$\rightarrow$ institution

State after separation unknown

Continuously with mother alone

Separated from mother

$\begin{array}{lll}3 & 2 & 28 \\ - & 1 & 3 \\ 7 & 5 & 2 \\ 2 & 1 & 1 \\ 7 & 1 & - \\ - & - & 2 \\ 2 & - & - \\ 16(76.2 \%) & 8(80 \%) & 8(22.2 \%)\end{array}$


the effects of early and late separation, the intermediate group of 10 children separated at age 2-5 years was omitted.

\section{Separation and personality}

In 1988 personality was assessed with the Freiburg Personality Inventory (FPI) and subjects separated from their parents were compared with never-separated controls. There were several tendencies in the expected direction, which, however, never reached significance: separated subjects described themselves as somewhat more nervous, depressed and labile, and as slightly less sociable. A comparison between 21 subjects separated in early childhood and 36 separated at school age did not yield any significant differences between these groups.

The findings on personality are confirmed by the SCL90R (Derogatis 1977), which from 1978 to 1988 was given six times to the subjects. When repeatedly given, this test has been considered to measure negative affectivity as a constant characteristic of personality (Watson and Clark 1984). Never during 10 years were there any significant differences between subjects separated from their parents in childhood vs controls on the scales of somatization, interpersonal sensitivity, depression, anxiety, anger, and total score. Neither did the subjects separated in early childhood differ from those separated at school age.

\section{Separation and psychopathology}

There was no association of longitudinally assessed psychopathology concerning diagnoses of anxiety and depression with separation and none when subjects were divided into those separated before age 2 years and at school age. The number of sociopathic subjects was too small for a comparison.

\section{Association of separation with a family strain score}

Our family strain score (Table 2) contains 15 items; each was given a value of 1 point. In contrast to results for personality and psychopathology, the report of the subjects who had been separated from their parents was less satisfactory than of those who were not. There were almost twice as many adverse influences reported by the former group. There was, however, no difference regarding family strain reported by the early separated vs those separated at school age.

Association of family strain with personality and psychopathology

In Table 3, FPI and family strain score are correlated for all 416 subjects who in 1988 gave both sets of data.

In contrast to a report of separation, a report of family strain is associated with scores indicating more lability
Table 2 Association of separation with Family Strain score (1988)

Family Strain Score items

Chronic illness: Fathe

Mother

Sibs

Psychiatric illness: Father

Mother

Parental discord

Severe conflict with parents

Childhood sexual abuse

Sib's severe conflict with parents

Other severe conflicts in family

Severe financial problems in family

Family not well regarded

More severely punished than other children

Felt neglected by parents

\begin{tabular}{lccl}
\hline & $n$ & $n$ & $\begin{array}{c}\text { Mann Whitney } \\
\text { U-Test }(p)\end{array}$ \\
\hline $\begin{array}{l}\text { Separation vs } \\
\text { no separation }\end{array}$ & 57 & 367 & \\
$\begin{array}{l}\text { Mean no. of items } \\
\begin{array}{l}\text { Early separation vs } \\
\text { late separation }\end{array}\end{array}$ & 4.23 & 2.34 & 0.0000 \\
\begin{tabular}{l} 
Mean no. of items \\
\hline
\end{tabular} & 4.00 & 36 & \\
\hline
\end{tabular}

Table 3 Association of the Family Strain scale with Freiburg Personality Inventory scores (Spearman correlations; $n=416$ )

\begin{tabular}{|c|c|c|}
\hline Scales & $r$ & $p$ \\
\hline Nervousness & 0.29 & 0.0001 \\
\hline Aggressivity & 0.15 & 0.002 \\
\hline Depressiveness & 0.31 & 0.0001 \\
\hline Excitability & 0.22 & 0.0001 \\
\hline Sociability & -0.04 & n.s. \\
\hline Resilience & -0.15 & 0.002 \\
\hline Dominance & -0.07 & n.s. \\
\hline Inhibition & 0.13 & 0.007 \\
\hline Frankness & 0.10 & 0.04 \\
\hline E Extroversion I & 0.02 & n.s. \\
\hline N Neuroticism I & 0.31 & 0.0001 \\
\hline M Masculinity & -0.20 & 0.0001 \\
\hline S1 Aggression ${ }^{\text {a }}$ & 0.15 & 0.003 \\
\hline \$2 Extroversion II ${ }^{\mathrm{a}}$ & -0.10 & 0.04 \\
\hline S3 Autonomous lability & 0.30 & 0.0001 \\
\hline
\end{tabular}

a From Angst and Clayton (1986)

and neuroticism, more depressiveness, less resilience, and less masculinity. The correlations of family strain with negative affectivity appear very clearly in six SCL-90R total scores over 10 years (1978-1988). With remarkable consistency family strain score was positively correlated with total score (Table 4).

In contrast to separation, reported family strain was also strongly associated with a longitudinal diagnosis of depression and/or anxiety (Table 5). 
Table 4 Association of the Family Strain score (1988) with SCL90 total scores $1978-1988$ (Spearman correlations)

\begin{tabular}{llll}
\hline Year & $n$ & $r$ & $p$ \\
\hline 1978 & 418 & 0.25 & 0.0001 \\
1979 & 387 & 0.22 & 0.0001 \\
1980 & 386 & 0.27 & 0.0001 \\
1981 & 355 & 0.26 & 0.0001 \\
1986 & 392 & 0.27 & 0.0001 \\
1988 & 405 & 0.32 & 0.0001 \\
\hline
\end{tabular}

Table 5 Family Strain score (FS; 1988) and a longitudinal diagnosis of depression and/or anxiety (1979-1988)

\begin{tabular}{lllll}
\hline & & $n$ & FS mean & Wilcoxon $(p)$ \\
\hline Depression & No & 306 & 2.25 & 0.0001 \\
& Yes & 118 & 3.47 & \\
\multirow{4}{*}{ Anxiety } & No & 304 & 2.35 & 0.0039 \\
& Yes & 120 & 3.20 & \\
\hline
\end{tabular}

Association of reported childhood problems with separation, family strain, personality, and psychopathology

At the interview of 1986, where 457 person participated, five questions were given on childhood fears and anxieties and on popularity, and seven questions on disciplinary problems at school, police contacts, and stealing. There was no association of reported childhood emotional problems with earlier or later separation from parents (Table 6). The number of separated children was too small to assess an association with reported behavioral problems.

Remembered emotional problems in childhood were associated with reported family strain, though the former were assessed in 1986 and the latter in $1988(r=0.22, p \leq$ 0.0001 ). A report of behavioral problems, on the other hand, was not significantly associated with strain.

Emotional and behavioral problems in childhood reported in 1986 were correlated with deviations in the FPI in 1988. There were 417 subjects with both sets of data. Emotional problems were associated with significant personality deviation (Table 7) on seven of nine scales, and this on secondary scales as well as regarding factors. An association with behavioral problems was, on the other hand, present for aggressivity ( $p \leq 0.0001)$, sociability ( $p \leq$ $0.007)$, inhibition $(p \leq 0.0001)$, frankness $(p \leq 0.0001)$, extroversion I ( $p \leq 0.0004)$, masculinity $(p \leq 0.002)$, and extroversion II $(p \leq 0.0001)$. Subjects who had reported childhood behavior problems appeared more aggressive, but also more sociable, less inhibited, more frank, extroverted, and masculine.

The level of childhood emotional problems as reported in 1986 was correlated without exception with the total score of SCL-90R over 10 years (Table 8). This association of current negative affectivity with a history of childhood emotional problems was much stronger than with one of behavioral problems.

Table 6 Definition, weighing, and distribution of reported childhood emotional and behavioral problems (1986) and association with separation

Scale of emotional (internalizing) problems:

Interview 1986

Afraid of teacher

Afraid of gymnastics

Afraid of swimming

Unpopular

Generally more anxious than peers

Weight

2

3

3

4

3

15

Scale of behavioral (externalizing) problems:

Interview 1986

Could not sit still at school

Disciplinary problems

Playing truant

Severe fights

Ran away from home

Contacts with police

Repeated stealing

$\begin{array}{lc} & \text { Weight } \\ & 1 \\ & 2 \\ & 3 \\ & 3 \\ & 3 \\ \text { negligible } & 1 \\ \text { relevant } & 5 \\ & 4 \\ & 22\end{array}$

Separation and emotional childhood problems:

\begin{tabular}{lrll}
\hline & $n$ & $\begin{array}{l}\text { Problem } \\
\text { score } \\
\text { (mean) }\end{array}$ & $\begin{array}{l}\text { Kruskal- } \\
\text { Wallis Test }\end{array}$ \\
\hline No separation & 360 & 2.54 & \\
Eearly separation (0-2 years) & 21 & 2.5 & n.s. \\
Late separation (6-15 years) & 36 & 3.17 & \\
\hline
\end{tabular}

Table 7 Association of reported emotional problems in childhood (1986) with Freiburg Personality Inventory (FPI) scales (1988); Spearman correlations; $n=416$

\begin{tabular}{lrl}
\hline FPI & \multicolumn{2}{c}{ Emotional problems } \\
\cline { 2 - 3 } & $r$ & $p$ \\
\hline Nervousness & 0.22 & 0.0001 \\
Aggressivity & 0.10 & 0.04 \\
Depressiveness & 0.27 & 0.0001 \\
Excitability & 0.17 & 0.006 \\
Sociability & -0.14 & 0.004 \\
Resiliency & -0.17 & 0.0004 \\
Dominance & 0.06 & $n, s$. \\
Inhibition & 0.24 & 0.001 \\
Frankness & 0.06 & $\mathrm{n} . \mathrm{s}$. \\
E Extroversion I & -0.06 & $\mathrm{n} . \mathrm{s}$. \\
$n \quad$ Neuroticism I & 0.27 & 0.001 \\
M Masculinity & -0.30 & 0.001 \\
S1 Aggression & 0.11 & 0.02 \\
S2 Extroversion II & -0.23 & 0.001 \\
S3 Autonomous lability & 0.27 & 0.001 \\
\hline
\end{tabular}


Table 8 Association of reported emotional and behavioral problem scores (1986) with SCL-90R total scores (1978-1988; Spearman correlations)

\begin{tabular}{llll}
\hline SCL-90R & $n$ & \multicolumn{2}{l}{ Emotional problems } \\
\cline { 3 - 4 } & & $r$ & $p$ \\
\hline 1978 & 447 & 0.21 & 0.0001 \\
1979 & 418 & 0.22 & 0.0001 \\
1980 & 413 & 0.24 & 0.0001 \\
1981 & 387 & 0.27 & 0.0001 \\
1986 & 427 & 0.23 & 0.0001 \\
1988 & 398 & 0.28 & 0.0001 \\
\hline
\end{tabular}

NOTE: The correlation of the behavioral problem score with SCL90R total score was significant only in 1980 and $1981(p \leq 0.01$ and 0.02 )

Table 9 Childhood emotional problems (EPS; 1986) and a longitudinal diagnosis of depression and/or anxiety (1979-1988)

\begin{tabular}{lllll}
\hline & & $n$ & EPS mean & Wilcoxon $(p)$ \\
\hline Depression & No & 332 & 2.06 & 0.0001 \\
& Yes & 125 & 3.58 & \\
\multirow{4}{*}{ Anxiety } & No & 328 & 2.18 & 0.002 \\
& Yes & 129 & 3.24 & \\
\hline
\end{tabular}

Table 10 Multivariate $\log$-linear analyses of the association of psychopathology in young adults over 10 years with childhood conditions

\begin{tabular}{|c|c|c|c|c|}
\hline & \multirow[t]{2}{*}{$d f$} & \multicolumn{3}{|c|}{ Depression } \\
\hline & & $\chi^{2}$ & Estimate & $p$ \\
\hline Intercept & 1 & 39.37 & 2.533 & 0.0000 \\
\hline Family strain & 1 & 7.75 & -0.134 & 0.0054 \\
\hline $\begin{array}{l}\text { Childhood emotional } \\
\text { problems }\end{array}$ & 1 & 11.57 & -0.115 & 0.0007 \\
\hline $\begin{array}{l}\text { Childhood behavioral } \\
\text { problems }\end{array}$ & & 9.25 & -0.047 & 0.0024 \\
\hline \multirow[t]{3}{*}{ Separation } & 2 & 0.92 & -0.250 & n.s. \\
\hline & $d f$ & \multicolumn{3}{|c|}{ Anxiety } \\
\hline & & $\chi^{2}$ & Estimate & $p$ \\
\hline Intercept & 1 & 16.53 & 1.627 & 0.0000 \\
\hline Family strain & 1 & 5.76 & -0.112 & 0.01 \\
\hline $\begin{array}{l}\text { Childhood emotional } \\
\text { problems }\end{array}$ & 1 & 6.24 & -0.082 & 0.01 \\
\hline $\begin{array}{l}\text { Childhood behavioral } \\
\text { problems }\end{array}$ & & 0.00 & -0.00 & n.s. \\
\hline Separation & 2 & 0.82 & -0.21 & n.s. \\
\hline
\end{tabular}

Childhood emotional problems were also associated with a longitudinal diagnosis of depression and anxiety over 10 years while there was no such association for behavioral problems (Table 9).
Results of a multivariate $\log$-linear analysis

In Table 10 the independent associations of childhood conditions with a longitudinal diagnosis of anxiety and depression is presented by a multivariate log-linear analysis. Behavioral problems appear associated with later depression, but not with anxiety. For both diagnostic groups significant conditions are reported family strain and reported emotional problems in childhood. Separation is not connected with later psychopathology.

\section{Discussion}

One of the main deficiencies of this study regards its being based on retrospective childhood data. As far as living with both natural parents or being definitely separated from at least one of them before age 16 years is concerned - i.e., structural data - the report of our subjects deserves, however, some confidence. A rate of $15.8 \%$ of subjects born in 1958-1959 who reported not having lived with both parents up to age 16 years compares well with a rate of $14.1 \%$ found in a sample of over 6000 unselected young Swiss adults born in 1952 (Ernst and Angst 1983).

Reported family disadvantage and emotional or behavioral problems in childhood may depend more on the actual mood of the subjects than structural data. Birtchnell et al. (1988) showed, however, that negative childhood reports of depressive women were confirmed by their sisters. Bleuler (1972) in his seminal work on schizophrenia obtained data from relatives and found an acceptable objective content of retrospective childhood reports. Rodgers (1996) concluded from a large national follow-up of children to age 43 years that distorted recall was not responsible for an association of early lack of care with adult depression.

A second deficiency of our study is that separation from parents particularly among older children generally led to staying with mother alone. Definite separation from mother mainly involved the youngest children, who thus appear as the group most in danger for an unfavorable development. They were also the group with the greatest number of institutionalizations. This group, however, is small; thus, a disadvantage may not be discovered for statistical reasons.

A third deficiency of our study consists of the fact that there were few subjects with sociopathy in the sample, so that an association with early or later separation could not be ascertained.

The main result of the present study is the finding that the structural variable of both early and late separation by themselves carry little weight for later psychopathology. Adult personality, negative affectivity, anxiety, and depression (the latter disorders diagnosed over 10 years and with a wide definition) seem independent of the mere fact of early and late separation, though, as mentioned previously, separation at age 0-2 years, in opposition to separation at school age, mostly involved separation from mother. 
In opposition to separation, a report of family disadvantage was connected with a certain amount of personality deviation, with negative affectivity, and with a longitudinal diagnosis of anxiety and depression. The same was true of a report of emotional problems concerning anxiety and not being popular with peers. This latter relationship validates to some degree the few questions on childhood anxiety and unpopularity that we gave the subjects. Masten and Coatsworth (1995) showed that not being popular with other children was associated with a strong risk of later disorder. Anxiety is a well-known precursor of depression (Angst and Wicki 1992), and early anxiety tends to persist over the lifetime (Angst and Vollrath 1991).

In agreement with other studies (Huesman et al 1984; Zoccolillo et al 1992), in the data presented herein, behavioral childhood problems carry a risk of later depression, but not of anxiety. The relationship appeared only in the multivariate $\log$-linear analysis and is an indicator of the validity of a very short inquiry regarding behavior at school.

There was a strong association of separation with family stress and a slight one with emotional disorder. As is clearly demonstrated by the multivariate log-linear analysis, separation by itself, whether early or late, does not carry a risk in the absence of family strain and emotional problems in childhood. Thus, variables concerning family structure do not interfere with adult mental health in the absence of family strain, and the bridge between unfavorable childhood conditions and adult psychiatric disorder are emotional and behavioral problems in childhood. With this result the present small and retrospective study is in line with a large number of methodically more relevant longitudinal investigations (Ernst and von Luckner 1985; Ernst 1993) and in particular with the results of the school of George Brown (Harris et al. 1986) and with the data from Kessler et al.'s (1993) Michigan Survey. Separation is traumatic inasmuch as it indicates earlier and later persistent stress, but is not by itself a traumatic experience. It is not family structure (whether a family is complete, incomplete, or broken) that influences development but the familial emotional climate and the way a child responds to it.

Acknowledgement This work was supported by grant 32-33 580.92 from the Swiss National Science Foundation.

\section{References}

American Psychiatric Association (1987) Diagnostic and statistical manual of mental disorders (DSM-III-R), 3rd edn, revised. American Psychiatric Press, Washington, DC

Angst J, Clayton PI (1986) Premorbid personality of depressive, bipolar and schizophrenic patients. Compr Psychiatry $27: 522-$ 532

Angst J, Vollrath M (1991) The natural history of anxiety disorders. Acta Psychiatr Scand 48:446-452

Angst J, Wicki W (1992) The Zurich Study XIII. Recurrent brief anxiety. Eur Arch Psychiatry Clin Neurosci 241 :296-300

Angst J, Dobler-Mikola A, Binder J (1984) The Zurich Study: a prospective epidemiological study of depressive, neurotic and psychosomatic syndromes. I. Problem, methodology. Eur Arch Psychiatr Neurol Sci 234:13-20

Angst J, Merikangas K, Scheidegger P, Wicki W (1990) Recurrent brief depression: a new subtype of affective disorder. J Affect Disord 19:87-98

Birtchnell J, Evans, Kennard J (1988) Life history factors associated with neurotic symptomatology in rural community sample of 40-49-year-old women. J Affect Disord 14:271-285

Bleuler M (1972) Die schizophrenen Geistesstörungen. Thieme, Stuttgart, p 143

Bowlby I (1951) Maternal care and mental health. WHO, Geneva

Derogatis LR (1977) SCL-90. Administration, scoring and procedures manual for the $\mathrm{R}$ (revised) version and other instruments for the psychopathology rating scale series. Johns Hopkins University School of Medicine, Baltimore, MD

Ernst C (1993) Frühe Lebensbedingungen und spätere psychische Störungen. Die Beiträge der psychiatrischen Epidemiologie zu einer neuen Sicht der Frühkindheit. Nervenarzt 64:553-556

Ernst C, Angst J (1983) Birth order. Springer, Berlin Heidelberg New York

Ernst C, Luckner N von (1985) Stellt die Frühkindheit die Weichen? Enke, Stuttgart

Fahrenberg J, Selg H, Hampel R (1973) Das Freiburger Persönlichkeitsinventar FPI, 2. Aufl, Hogrefe, Göttingen

Harris T, Brown GW, Bifulco A (1986) Loss of parent in childhood and adult psychiatric disorder. Psychol Med 16:641-659

Huesman PL, Eron LD, Lefkowitz MM et al. (1984) The stability of aggression over time on generations. Dev Psychol 20:11201134

Kessler RC, Magee WJ (1986) Childhood adversities and adult depression: basic patterns of association in a US national survey. Psychol Med 23:679-690

Masten AS, Coatsworth JD (1995) Competence, resilience and psychopathology. In: Cicchetti D, Cohen DJ (eds) Developmental psychopathology, vol II. Wiley Interscience, New York, pp 715-751

Rodgers B (1996) Reported parental behaviour and adult affective symptoms. 1. Associations and moderating factors. Psychol Med $26: 51-61$

Rutter M, Graham P, Chadwick W (1976) Adolescent turmoil: fact or fiction? J Child Psychol Psychiatry 17:35-46

Spitz RA (1954) Die ersten Objektbeziehungen. Klett, Stuttgart

Steinhausen HC (1985) Psychiatric disorders in children and family dysfunction. Soc Psychiatry $20: 11-16$

Watson D, Clark LA (1984) Negative affectivity. The disposition to experience aversive emotional status. Psychol Bull 96:219235

Zoccolillo M, Pickles A, Quinton D, Rutter M (1992) Psychol Med $22: 971-986$ 